\title{
Development and validation of a UPLC-MS method for determination of atazanavir sulfate by the "analytical quality by design" approach
}

\author{
CHANDNI SAHA ${ }^{1 *}$ \\ N. VISHAL GUPTA \\ R. S. CHANDAN ${ }^{2}$ \\ ${ }^{1}$ Department of Pharmaceutics \\ JSS College of Pharmacy \\ JSS Academy of Higher Education $\mathcal{E}$ \\ Research, Mysuru, Karnataka 570015 \\ India \\ ${ }^{2}$ Department of Pharmaceutical \\ Chemistry, JSS College of Pharmacy \\ JSS Academy of Higher Education $\mathcal{E}$ \\ Research, Mysuru, Karnataka 570015 \\ India
}

\begin{abstract}
A UPLC-MS method for the estimation of atazanavir sulfate was developed using the "analytical quality by design" approach. The critical chromatographic quality attributes identified were retention time, theoretical plates and peak tailing. The critical method parameters established were percent of organic modifier, flow rate and injection volume. Optimization performed using Box-Behnken Design (BBD) established $10 \%$ organic modifier, $0.4 \mathrm{~mL} \mathrm{~min}^{-1}$ flow rate and $6-\mu \mathrm{L}$ injection volume as the optimum method conditions. Atazanavir sulfate eluted at $5.19 \mathrm{~min}$ without any interference. Method validation followed international guidelines. The method has proven linearity in the range of $10-90 \mu \mathrm{g} \mathrm{mL}{ }^{-1}$. Recovery was between $100.2-101.0 \%$ and precision within the accepted limits (RSD $0.2-0.7 \%$ ). LOD and $L O Q$ were 2.68 and $8.14 \mu \mathrm{g} \mathrm{mL}^{-1}$, resp. Stress testing stability studies showed atazanavir sulfate to degrade under acidic and basic conditions. The suggested technique is simple, rapid and sustainable. It is, therefore, suggested for routine analysis of atazanavir sulfate.
\end{abstract}

Keywords: atazanavir sulfate, UPLC-MS, "analytical quality by design"

Atazanavir sulfate is the first protease inhibitor with a simplified dosing profile (1). Protease inhibitors are among the most potent classes of antiretroviral drugs; however, due to their pill burden and side effects, the prescribing choice has shifted to non-nucleoside reverse transcriptase inhibitors. Recent developments in the fixed-dose combination and highly active antiretroviral therapy has made atazanavir sulfate a promising drug (2, 3). Atazanavir sulfate is chemically known as 3,12-bis(1,1-dimethylethyl)-8-hydroxy-4,11dioxo-9-(phenylmethyl)-6-[[4-(2-pyridinyl)phenyl]methyl]-2,5,6,10,13-pentaazatetradecane-dioic acid dimethyl ester. It has a favorable resistance profile that provides it with the advantage of being a first-line therapy drug (3). Having a large potential, the drug has been explored by determining its genotoxic impurities (4), determination in dried blood spot (5),

\footnotetext{
*Correspondence, e-mail: chandnisaha7@gmail.com
} 
some bioanalytical methods $(6,7)$, development of stability indicating methods $(8,9)$, assay method (10) and pharmacokinetic studies (11-13). However, method development through the "analytical quality by design" (AQbD) approach has not been addressed.

Overcoming the challenges of one factor at a time (OFAT), the QbD approach has amended the pharmaceutical quality management system (14). QbD systematically builds quality within the process, eliminating quality testing at the end of the process (15). QbD approach commences by defining the quality targets and identifying the critical quality attributes. The paradigm advances by identifying the critical process and material parameters through sound risk assessment studies (16), further through the concept of experimental designs/design of experiments (DOE); as a result, the multifactor effects on selected responses are observed. DOE also reduces the number of experiments to be performed when a large number of factors (inputs) are involved (14). The concept of QbD has been present in various industries since the 1970s but was introduced into the pharmaceutical industry in 2004 through Pharmaceutical cGMPs for the 21st Century initiative (17); it is also reflected in ICH Q8-Q10 guidelines (18-20). The QbD approach has been adopted as "analytical quality by design" (AQbD) for analytical method development with peripheral alterations in terminologies (21).

The focus of this paper is therefore to maneuver the paramount advantages of $\mathrm{QbD}$ to analytical method development using ultra performance liquid chromatography-mass spectrometry (UPLC-MS). Method development through the AQbD approach for the determination of atazanavir sulfate constitutes the novelty of this paper. Unlike the existing methods for determination of atazanavir sulfate, the current method avoids the use of complex buffer systems; thus, the use of a simple mobile phase adds to the novelty of the paper.

\section{EXPERIMENTAL}

\section{Chemicals and samples}

The gift sample of atazanavir sulfate, active pharmaceutical ingredient, was received from Laurus Labs, India. Atazanavir sulfate capsules, Atazor $300 \mathrm{mg}$, from Emcure Pharmaceuticals Ltd., India, were obtained from the local market. Thermo Fisher Scientific, USA, furnished LCMS grade acetonitrile. GR grade ammonium acetate was from Merck, Germany. HPLC type I water was from the Millipore Direct- $Q^{\circledR} 3$ UV water purification system, Merck Millipore, Germany.

\section{Chromatographic conditions and apparatus}

Acquity UPLC ${ }^{\circledast}$ (Waters, USA) using a reverse-phase Acquity UPLC BEH C18 $(1.7 \mu \mathrm{m}$, $1 \mathrm{~mm} \times 50 \mathrm{~mm}$ ) column coupled in-line with a Synapt G2 (Waters, USA) mass spectrometer aided by a high resolution quantitative time-of-flight (QuanTof ${ }^{\mathrm{TM}}$ ) analyzer and featuring an ultra-fast electron multiplier, hybrid analog-to-digital (ADC) detector, was used for all chromatographic separations. Electrospray ionization interface in positive mode directed column eluent to the mass spectrometer. The mass spectrometer operated in sensitivity mode using capillary voltage of $1.8 \mathrm{kV}$ and cone voltage of $17 \mathrm{~V}$. The desolvation gas flow rate was $300 \mathrm{~L} \mathrm{~h}^{-1}$, while the source and desolvation gas temperature were 100 and $200{ }^{\circ} \mathrm{C}$, 
resp. The gradient mode mobile phase was composed of $10 \mathrm{mmol} \mathrm{L}^{-1}$ ammonium acetate as solvent $\mathrm{A}$ and acetonitrile as solvent $\mathrm{B}$. Organic modifier percent, mobile phase flow rate and injection volume were varied according to the experimental runs from DOE.

\section{Preparation of standard stock solution}

Standard stock solution of $1.0 \mathrm{mg} \mathrm{mL}^{-1}$ was obtained by dissolving accurately weighed atazanavir sulfate in water. Serial dilutions of the standard stock solution gave working standards between 10 and $100 \mu \mathrm{g} \mathrm{mL} \mathrm{m}^{-1}$. Working standards were filtered using $0.2-\mu \mathrm{m}$ Phenex PTFE syringe filters (Phenomenex, USA) before being injected.

\section{Method development using the AQbD approach}

The first step in the AQbD approach is to define the objectives of the method, collectively termed as analytical target profile (ATP)/quality target method profile (QTMP) (2224). The ATP of the current method was to develop a simple, accurate, precise, robust and specific method meeting the critical quality attributes (CQAs). CQAs are the most vital parameters that, within their defined limits, ensure the quality of the method (29). The CQAs identified for the suggested UPLC-MS method development were retention time, theoretical plates and peak tailing. The acceptance criterion for theoretical plates was $>2000$ and $<2$ for peak tailing $(26,27)$. Further, risk factors identification through initial trials, risk analysis through Ishikawa/fish bone diagram and evaluation by failure mode and effect analysis (FMEA) were used to uncover the high risk factors as critical method parameters (CMPs).

Initial screening of factors through fraction factorial design (FFD). - Initial screening of factors/method parameters aids to discover the CMPs that significantly cause variations in CQAs and eliminates factors which are just noise. Fraction factorial design (FFD), resolution IV with one generator $\left(2^{4-1}\right)$ from Design Expert ${ }^{\circledR}$ v.11.0 software produced eight experimental runs for the initial screening of four factors at two levels. The factors at their low and high levels were organic modifier: 10 and $30 \%$, flow rate: 2 and $6 \mathrm{~mL} \mathrm{~min}^{-1}$, injection volume: 0.2 and $0.6 \mu \mathrm{L}$ and column temperature: 25 and $45^{\circ} \mathrm{C}$. Using Pareto charts and model significance values, the significant factors were resolved.

Optimization of selected factors using the Box-Behnken design (BBD). - The significant factors, organic modifier (at 10 and $30 \%$ ), flow rate $\left(2\right.$ and $\left.6 \mathrm{~mL} \mathrm{~min}^{-1}\right)$ and injection volume $(0.2$ and $0.6 \mu \mathrm{L})$, were optimized at their low and high levels using BBD; they produced 17 experimental runs. These experiments were performed using $50 \mu \mathrm{g} \mathrm{mL}{ }^{-1}$ working standard solution of atazanavir sulfate. The results were analyzed by goodness of fit $\left(R^{2}\right)$, $p$-values, adjusted $R^{2}$ and predicted $R^{2}$, and the lack-of-fit values by Design Expert ${ }^{\circledR}$ v.11.0 software. Variations in CQA were comprehended through contour plots and 3D graphs. Numerical optimization was used to optimize and select the method conditions best fitting the CQAs with desirability near one. Criteria for optimization of retention time and peak tailing were selected to be "in range" of their minimum to maximum values obtained during the experiments, while the criterium was set to the maximum value for theoretical plates. Graphical optimization with $99 \%$ tolerance assisted exploring the design space within the set criteria. 


\section{Analytical method validation}

Following ICH Q2(R1) guidelines (28), parameters like linearity, accuracy, precision, limit of detection $(L O D)$, limit of quantification $(L O Q)$ and selectivity were assessed during the method validation. AQbD approach provides the advantage of establishing the design space, a region within which any changes to factor (CMP) values do not significantly affect the method development, thus, incorporating robustness into the process and, therefore, testing of robustness at the end of method development can be omitted (18).

Linearity. - Working standard solutions prepared in the range of $10-100 \mu \mathrm{g} \mathrm{mL}^{-1}$ were filtered through a 0.2-micron syringe filter and injected into the chromatograph, each in 3 replicates. Total ion chromatograms (TIC) were obtained and the calibration curve was plotted to establish the linear relationship by the least squares method.

Accuracy. - Accuracy was tested using the standard addition method. The capsule formulation sample was spiked with a known amount of the active pharmaceutical ingredient at $80 \%\left(40 \mu \mathrm{g} \mathrm{mL}^{-1}\right), 100 \%\left(50 \mu \mathrm{g} \mathrm{mL}^{-1}\right)$ and $120 \%\left(60 \mu \mathrm{g} \mathrm{mL}^{-1}\right)$. The resultant solution was analyzed in six replicates. Percentage recoveries were calculated and reported (Table III).

Precision. - The intra-day and intermediate (inter-day) precision were calculated from the peak areas of 40,50 and $60 \mu \mathrm{g} \mathrm{mL}^{-1}$ working standard solutions of atazanavir sulfate, injected on the same day and on two consecutive days, resp. $(n=6)$. Similarly, precision of the formulation analysis using 40, 50 and $60 \mu \mathrm{g} \mathrm{mL}^{-1}$ solutions of Atazor was measured.

LOD and LOQ. - LOD and LOQ were calculated using calibration curve data, following the formula $L O D=3.3 \times \mathrm{SD} /$ slope and $L O Q=10 \mathrm{xD} /$ slope, where $\mathrm{SD}$ is the standard deviation of the regression line $(29,30)$.

Selectivity. - Selectivity of the method was demonstrated by injecting the blank, working standard solution and sample (commercial formulation) solution and monitoring the elution of analyte.

\section{Stability testing (stress conditions)}

Pursuant to ICH Q1A (R1) and ICH Q1 B guidelines (31, 32), stress testing of the drug substance can help identify the likely degradation products, which can in turn help establish the degradation pathways and the intrinsic stability of the molecule and validate the stability indicating power of the analytical procedure used.

Acid, base and thermal (moist heat) degradation. - Ten mg of atazanavir sulfate was dissolved in $10 \mathrm{~mL} 0.1 \mathrm{~mol} \mathrm{~L}^{-1} \mathrm{HCl}, 0.1 \mathrm{~mol} \mathrm{~L}^{-1} \mathrm{NaOH}$ and water, resp., in a round bottom flask and refluxed at $80{ }^{\circ} \mathrm{C}$ for $60 \mathrm{~min}$. Samples were collected at $60 \mathrm{~min}$ and cooled to room temperature $\left(28^{\circ} \mathrm{C}\right)$. The acid and base degraded samples were then neutralized with 0.1 mol L-1 $\mathrm{NaOH}$ and $0.1 \mathrm{~mol} \mathrm{~L}^{-1} \mathrm{HCl}$, resp. All samples were further diluted with water to 50 $\mu \mathrm{g} \mathrm{mL} \mathrm{m}^{-1}$, sonicated for $5 \mathrm{~min}$, filtered and injected into the UPLC-MS system.

Oxidative degradation. - Ten mg of atazanavir sulfate reacted with $10 \mathrm{~mL}$ of $3 \%$ and 30 $\% \mathrm{H}_{2} \mathrm{O}_{2}$ separately in two round bottom flasks at room temperature $\left(28^{\circ} \mathrm{C}\right)$ for $60 \mathrm{~min}$. 
Samples collected after 60 min were cooled to room temperature $\left(28^{\circ} \mathrm{C}\right)$, diluted with water to $50 \mu \mathrm{g} \mathrm{mL}{ }^{-1}$, sonicated for $5 \mathrm{~min}$, filtered and injected into the UPLC-MS system.

Photolytic degradation. - Ten mg of atazanavir sulfate in a clean quartz tube was placed under UV light $(320 \mathrm{~nm})$ for 1 day. The drug was sampled thereafter, dissolved in water to a concentration of $1.0 \mathrm{mg} \mathrm{mL}^{-1}$ and further to $50 \mu \mathrm{g} \mathrm{mL} \mathrm{m}^{-1}$. This solution was sonicated for $5 \mathrm{~min}$, filtered and injected into UPLC-MS.

\section{RESULTS AND DISCUSSION}

\section{Risk assessment studies}

In order to develop a method within the acceptable range of CQAs, it is essential to have a thorough understanding of the method parameters and their effects. A risk assessment study methodically identifies the factors/parameters that can have a substantial effect on the CQAs. ICH Q9 lists 9 risk management tools (19), of which the Ishikawa/fishbone diagram and failure mode and effect analysis (FMEA) are extensively used in the $\mathrm{QbD}$ approach (33). The Ishikawa diagram/fishbone diagram dissects the method development process into various fractions such as men, material, method, etc., and each fraction provides an insight into factors/parameters that can affect the CQAs. Further, FMEA aids to rank and prioritize these factors into low, medium, and high risks based on a composite score called the risk priority number (RPN). The RPN is calculated based on the impact of risk on the method, frequency of occurrence and the ability to detect the failure (impact * occurrence * detectability) (14).

In the present method, initial trials, Ishikawa diagram/fishbone diagram (Fig. 1) and FMEA tools, resp., identified, analyzed and prioritized the risk factors associated with the method development process. Using the knowledge from initial trails, identified risks were evaluated for their impact, occurrence, and detection, to calculate the RPN. Factors that

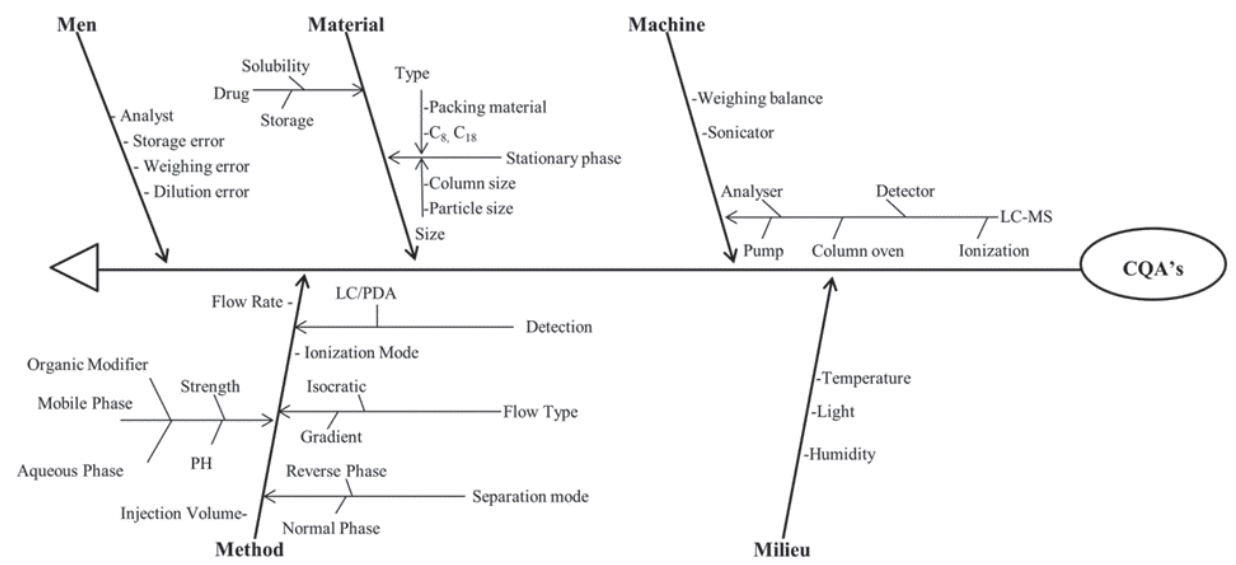

Fig. 1. Ishikawa diagram/fishbone diagram for estimating the parameters affecting CQAs. 
C. Saha et al.: Development and validation of a UPLC-MS method for determination of atazanavir sulfate by the "analytical quality by design" approach, Acta Pharm. 70 (2020) 17-33.

Table I. Identifying high risk factors through the risk priority number (RPN)

\begin{tabular}{|c|c|c|c|c|c|}
\hline Factor/process & Failure affect (s) & 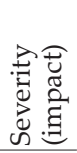 & 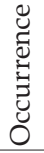 & 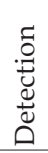 & $\underset{c}{Z}$ \\
\hline Solubility & Recovery, peak area, theoretical plates & 3 & 1 & 4 & 12 \\
\hline Sonication & Separation quality & 1 & 1 & 4 & 4 \\
\hline Ionization & Peak detection & 4 & 1 & 1 & 4 \\
\hline Organic modifier & Retention time, separation quality & 4 & 1 & 4 & 16 \\
\hline Organic modifier portion & Retention time, separation quality, peak area & 5 & 5 & 4 & 100 \\
\hline Injection volume & Peak area, separation quality, peak area & 5 & 5 & 4 & 100 \\
\hline Separation mode & Retention time, separation quality, peak area & 3 & 1 & 4 & 12 \\
\hline Flow type & Retention time & 3 & 1 & 4 & 12 \\
\hline Flow rate & Retention time, separation quality, peak area & 5 & 5 & 4 & 100 \\
\hline Column temperature & Separation quality & 4 & 5 & 4 & 80 \\
\hline Column type & Retention time, separation quality, peak area & 4 & 1 & 4 & 16 \\
\hline
\end{tabular}

RPN - risk priority number: $<43$ (low risk factors), 44-83 (medium risk), $>84$ (high risk).

Table II. Optimization through the Box-Behnken design: factor conditions and results

\begin{tabular}{cccccccc}
\hline \multirow{2}{*}{$\begin{array}{c}\text { Standard } \\
\text { run }\end{array}$} & $\begin{array}{c}\text { Run } \\
\text { order }\end{array}$ & $\begin{array}{c}\text { Organic } \\
\text { modifier }(\%)\end{array}$ & $\begin{array}{c}\text { Flow rate } \\
\left(\mathrm{mL} \mathrm{min}^{-1}\right)\end{array}$ & $\begin{array}{c}\text { Injection } \\
\text { volume }(\mu \mathrm{L})\end{array}$ & $\begin{array}{c}\text { Retention } \\
\text { time }(\mathrm{min})\end{array}$ & $\begin{array}{c}\text { Theoretical } \\
\text { plates }^{\text {a }}\end{array}$ & $\begin{array}{c}\text { Peak } \\
\text { tailing }\end{array}$ \\
\hline 15 & 1 & 20 & 0.4 & 4 & 4.92 & 6556 & 0.82 \\
16 & 2 & 20 & 0.4 & 4 & 4.91 & 6488.7 & 0.81 \\
12 & 3 & 20 & 0.6 & 6 & 4.37 & 7861.3 & 0.70 \\
10 & 4 & 20 & 0.6 & 2 & 4.37 & 6892 & 0.74 \\
6 & 5 & 30 & 0.4 & 2 & 4.29 & 6331 & 0.69 \\
13 & 6 & 20 & 0.4 & 4 & 4.7 & 6808.5 & 0.79 \\
1 & 7 & 10 & 0.2 & 4 & 7.22 & 6409.51 & 1.01 \\
5 & 8 & 10 & 0.4 & 2 & 5.2 & 7642.93 & 0.761 \\
7 & 9 & 10 & 0.4 & 6 & 5.21 & 9028 & 0.78 \\
4 & 10 & 30 & 0.6 & 4 & 3.6 & 6764 & 0.63 \\
3 & 11 & 10 & 0.6 & 4 & 4.71 & 6034.72 & 0.61 \\
11 & 12 & 20 & 0.2 & 6 & 6.4 & 6688.4 & 1.03 \\
8 & 13 & 30 & 0.4 & 6 & 4.29 & 7380.47 & 0.64 \\
9 & 14 & 20 & 0.2 & 2 & 6.37 & 5438.1 & 1.09 \\
14 & 15 & 20 & 0.4 & 4 & 4.92 & 6556 & 0.78 \\
2 & 16 & 20 & 0.4 & 4 & 4.92 & 6556 & 0.81 \\
\hline
\end{tabular}

CQAs - critical quality attributes

a Per column length. 
a)

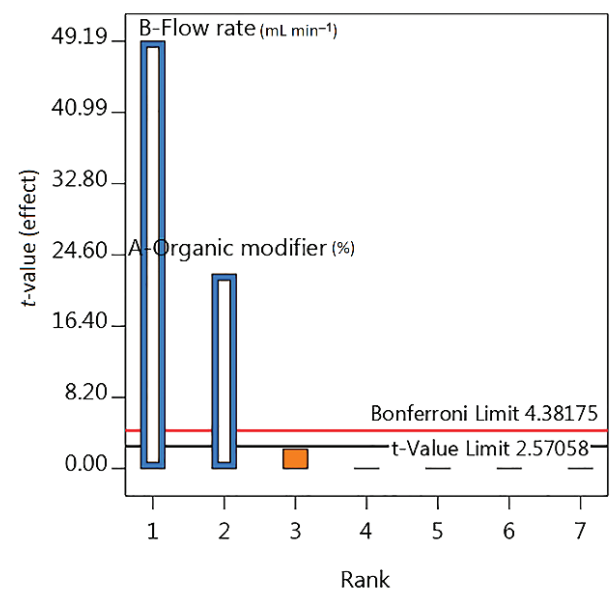

c)

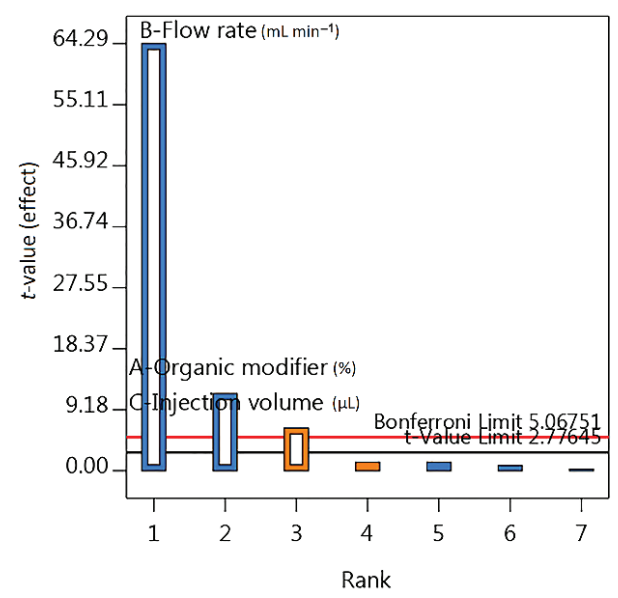

b)

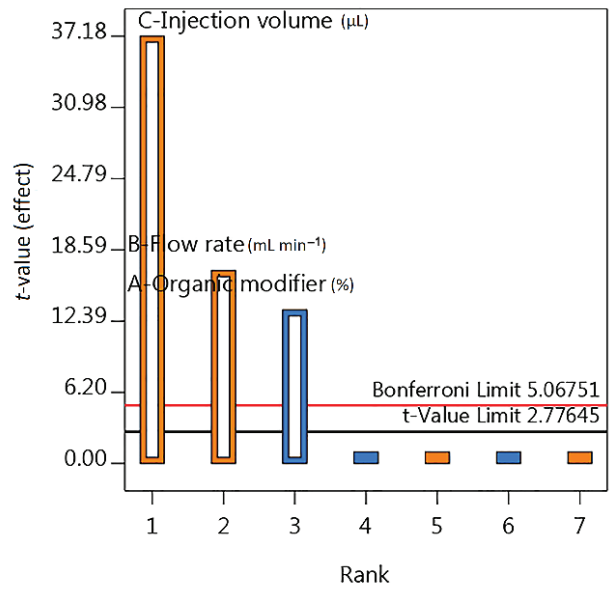

$\square$ Positive Effects

$\square$ Negative Effects

Fig. 2. Pareto chart representing the significance of risk factors on chosen CQAs: a) retention time, b) theoretical plates and c) peak tailing.

could have high severity (impact), high occurrence (probability) and low detectability were assigned the value of 5 on a scale of $1-5$ while factors showing low severity, low occurrence and high detectability scored near 1 . The RPN values classified the organic modifier percent, flow rate, and injection volume as highrisk factors while column temperature was a mediumrisk factor (listed in Table I). Further, these factors were screened using DOE.

Initial screening of factors through fraction factorial design (FFD). - The four factors screened through FFD $\left(2^{4-1}\right)$ showed a parallel relation between the main effects. Proving the lack of interactions, their evaluation followed the first-order polynomial equation given as follows: 
C. Saha et al.: Development and validation of a UPLC-MS method for determination of atazanavir sulfate by the "analytical quality by design" approach, Acta Pharm. 70 (2020) 17-33.

\section{Retention time (min)}

Design points above predicted value

Design points below predicted value 3.6

$\mathrm{X} 1$ = A: Organic modifier (\%) $\mathrm{X} 2=\mathrm{B}$ : Flow rate $\left(\mathrm{mL} \mathrm{min}^{-1}\right)$

\section{Actual factor}

C: Injection volume $=6 \mu \mathrm{L}$

\section{Theoretical plates}

Design points above predicted value O Design points below predicted value 3982.8 9028
Peak tailing

Design points above predicted value O Design points below predicted value 0.61 1.09 a)

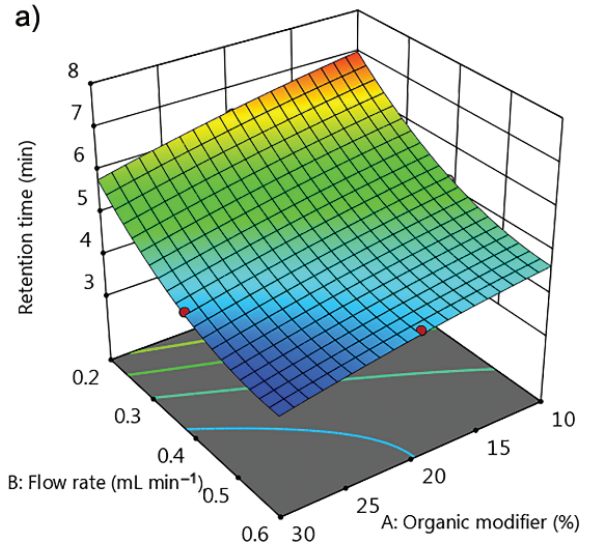

b)
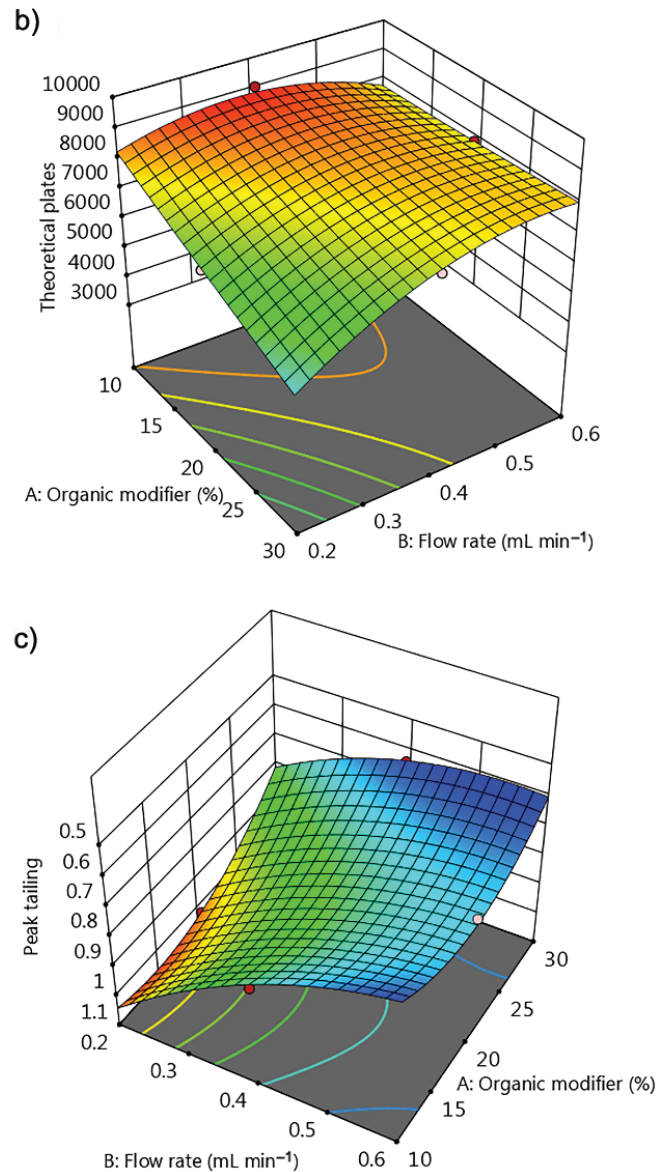

Fig. 3. 3D surface plots for responses: a) retention time, b) theoretical plates and c) peak tailing. 


$$
Y=\beta_{0}+\beta_{1}^{*} X_{1}+\beta_{2}{ }^{*} X_{2}+\beta_{3}{ }^{*} X_{3}+\beta_{4}{ }^{*} X_{4}
$$

where $\beta_{0}$ is the intercept and $\beta_{1}-\beta_{4}$ are coefficients of each factor, $X$ being the factor value and $Y$ is the response. The results were analyzed using a Pareto chart as shown in Fig. 2. It shows that the flow rate and organic modifier had a significant effect on retention time and theoretical plates, while the flow rate and injection volume influenced peak tailing. High $R^{2}$ values for retention time (0.9895), theoretical plates (0.9945) and peak tailing (0.9556) inferred that these factors caused significant variations in the CQAs; hence, optimization was carried out using these three factors. Column temperature did not influence the CQAs significantly and thus it was set to an intermediate value of $35^{\circ} \mathrm{C}$ during optimization experiments. Screening of factors prior optimization helps reduce the experimental burden and errors.

Optimization and design space. - The results presented in Table II revealed quadratic relations between the CMPs and the CQAs; thus, evaluation followed the second-order polynomial equation:

$$
Y=\beta_{0}+\beta_{1}{ }^{*} X_{1}+\beta_{2}{ }^{*} X_{2}+\beta_{3}{ }^{*} X_{3}+\beta_{4}{ }^{*} X_{1} X_{2}+\beta_{5}{ }^{*} X_{2} X_{3}+\beta_{6}{ }^{*} X_{1} X_{3} \beta_{7}{ }^{*} X_{1}{ }^{2}+\beta_{8}{ }^{*} X_{2}{ }^{2}+\beta_{9}{ }^{*} X_{3}{ }^{2}
$$

where $\beta_{0}$ is the intercept and $\beta_{1}-\beta_{9}$ are coefficients of each term, $X$ being the factor value and $Y$ is the response.

The results (Table II) were analyzed by analysis of variance (ANOVA) and fit statistics by observing their $p$-values and goodness of fit $\left(R^{2}\right)$, resp. The $R^{2}$ values for retention time (0.9883), theoretical plate $(0.9848)$ and peak tailing (0.9904), all being close to one and the $p$-values observed to be $<0.05$, justified the significant influence of CMPs on the variation in CQAs ( $p<0.05$ rejects the null hypothesis and accepts the alternative hypothesis that factors are significant). The difference between the adjusted $R^{2}$ and predicted $R^{2}$ found to be less than 0.2 indicated the absences of inflated factor inclusion in the model. Adjusted $R^{2}$ values decrease if insignificant factors are included in the model, causing an increased difference between adjusted and predicted $R^{2}$ values, which is an indication of a model with unnecessary factors. The lack of fit being not significant proved that the model was safe to explore the design space/method operable design region (MODR).

Influence of CMPs on retention time, theoretical plates and peak tailing was in curvilinear fashion as observed through the contour plots and 3D surface plots (Fig. 3). The 3D surface plots in Fig. 3a show long retention time towards lower organic modifier percent and short retention time towards higher organic modifier percent at increased flow rate. Theoretical plates were high in case of lower organic modifier percent, flow rate around

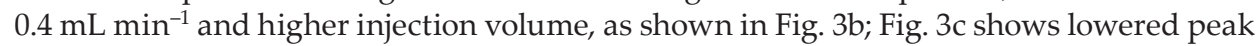
tailing at low and high organic modifier percent at a flow rate of $>0.4 \mathrm{~mL} \mathrm{~min}^{-1}$.

Numerical optimization was used to figure out the method conditions with desirability near one. The criteria during optimization were set to be "in range" of minimum to maximum values of the retention time and peak tailing obtained from 17 experiments, while maximum for theoretical plate. From the 2D contours plots in Fig. 4, we can interpret the area with high desirability (orange), low (blue) to high (orange) retention time, high (orange) theoretical plates and low (blue) peak tailing. Cumulatively from the results of 3D surface plot, numerical optimization and contour plots, the optimized method conditions 
C. Saha et al.: Development and validation of a UPLC-MS method for determination of atazanavir sulfate by the "analytical quality by design" approach, Acta Pharm. 70 (2020) 17-33.

\section{All responses \\ Design Points}

0.000

1.000

$\mathrm{X} 1$ = A: Organic modifier $(\%)$ $\mathrm{X} 2=\mathrm{B}$ : Flow rate $(\mathrm{mL} \mathrm{min}-1)$

\section{Actual factor}

C: Injection volume $=6 \mu \mathrm{L}$
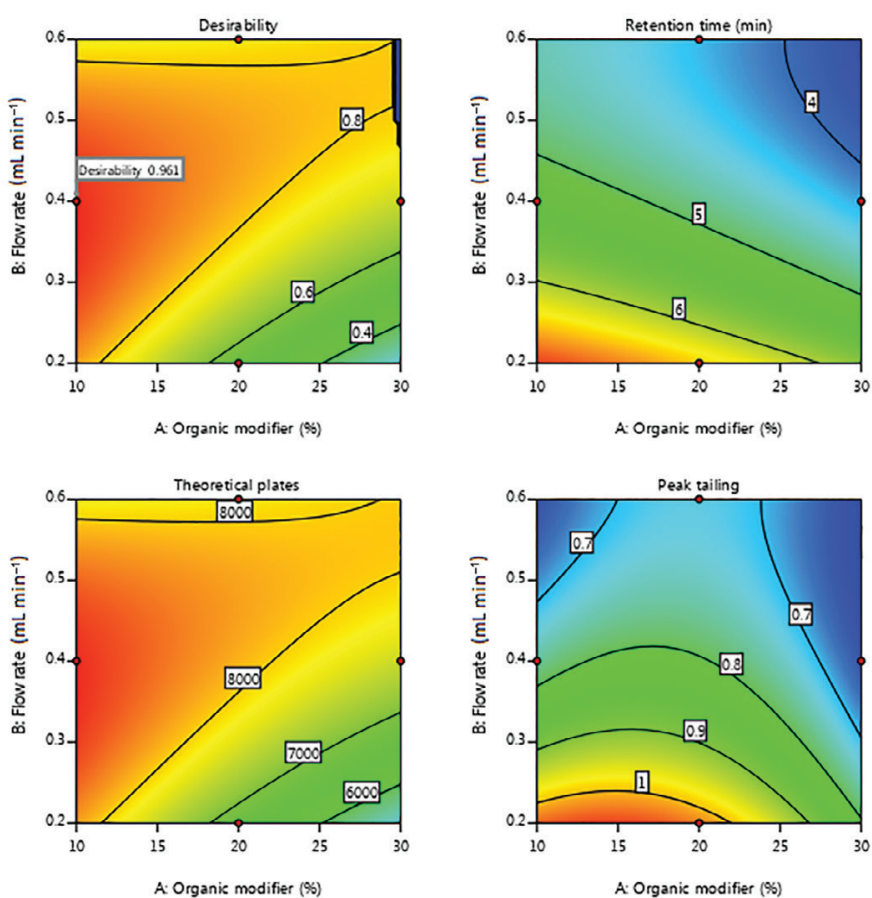

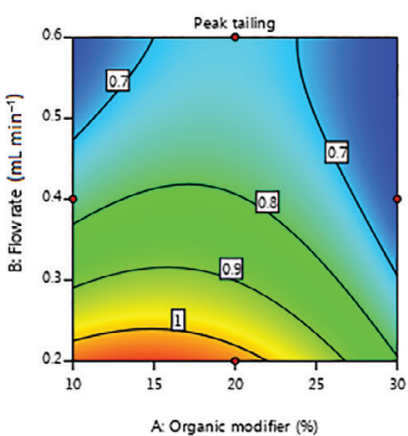

Fig. 4. 2D contour plots for desirability, retention time, theoretical plates/column length and peak tailing.

Overlay Plot
Retention time ( $\mathrm{min})$
$\Pi$ Low
$\Pi$ High
Theoretical plates
$\Pi$ Low
Peak tailing
$\Pi$ Low
$\Pi$ High
Design Points

$\mathrm{X} 1$ = A: Organic modifier (\%) $\mathrm{X} 2=\mathrm{B}$ : Flow rate $\left(\mathrm{mL} \mathrm{min}^{-1}\right)$

Actual Factor

$\mathrm{C}$ : Injection volume $=6 \mu \mathrm{L}$

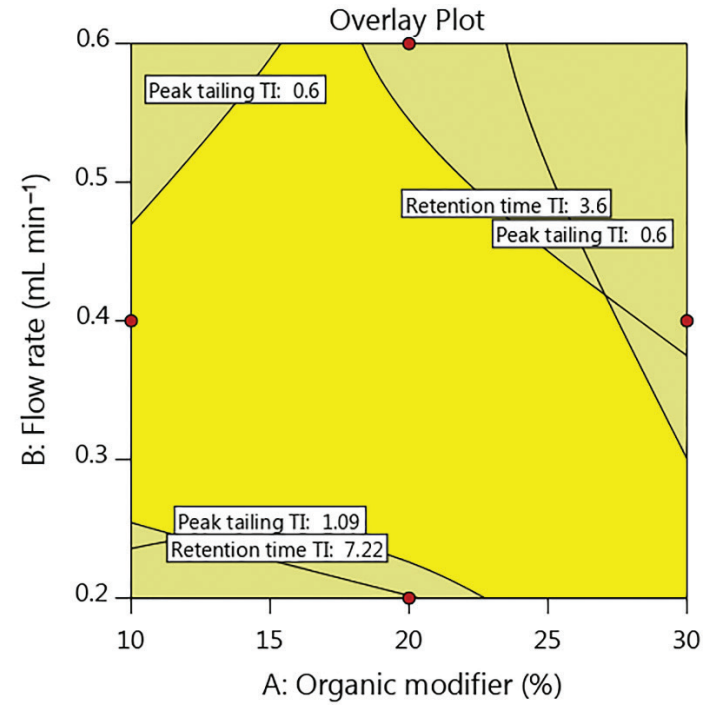

A: Organic modifier (\%)

Fig. 5. Overlay plot showing the method operable design region. 
C. Saha et al:: Development and validation of a UPLC-MS method for determination of atazanavir sulfate by the "analytical quality by design" approach, Acta Pharm. 70 (2020) 17-33.

Table III. Accuracy and precision studies

\begin{tabular}{|c|c|c|c|c|c|c|c|}
\hline $\begin{array}{l}\text { Formulation } \\
\text { sample } \\
\text { (atazanavir, } \\
\left.\mu \mathrm{g} \mathrm{mL} \mathrm{mL}^{-1}\right)^{\mathrm{b}}\end{array}$ & $\begin{array}{l}\text { RSD } \\
(\%)\end{array}$ & $\begin{array}{c}\text { Spiked } \\
\text { concentration } \\
\left(\mu \mathrm{g} \mathrm{mL} L^{-1}\right)\end{array}$ & $\begin{array}{c}\text { Total } \\
\text { concentration } \\
\text { found } \\
\left(\mu \mathrm{g} \mathrm{mL}^{-1}\right)^{\mathrm{b}}\end{array}$ & \multicolumn{2}{|c|}{$\begin{array}{l}\text { RSD } \\
(\%)\end{array}$} & \multicolumn{2}{|c|}{$\begin{array}{c}\text { Recovery } \\
(\%)\end{array}$} \\
\hline \multirow{5}{*}{$\begin{array}{c}50.5 \\
\left(50.0^{\mathrm{a}}\right)\end{array}$} & \multirow{3}{*}{0.5} & 40.0 & 90.8 & \multicolumn{2}{|c|}{0.2} & \multicolumn{2}{|c|}{100.4} \\
\hline & & 50.0 & 100.8 & \multicolumn{2}{|c|}{0.2} & \multicolumn{2}{|c|}{100.2} \\
\hline & & 60.0 & 111.2 & \multicolumn{2}{|c|}{0.3} & \multicolumn{2}{|c|}{100.5} \\
\hline & \multicolumn{3}{|c|}{ Concentration found $\left(\mu \mathrm{g} \mathrm{mL} L^{-1}\right)^{b}$} & \multicolumn{4}{|c|}{ RSD (\%) } \\
\hline & \multicolumn{2}{|c|}{ Intra-day } & Inter-day & \multicolumn{2}{|c|}{ Intra-day } & \multicolumn{2}{|c|}{ Inter-day } \\
\hline $40.0^{\mathrm{a}}$ & & 40.2 & 40.3 & \multicolumn{2}{|c|}{0.3} & \multicolumn{2}{|c|}{0.5} \\
\hline $50.0^{\mathrm{a}}$ & & 50.3 & 50.3 & \multicolumn{2}{|c|}{0.7} & \multicolumn{2}{|c|}{0.7} \\
\hline $60.0^{\mathrm{a}}$ & & 60.2 & 60.3 & \multicolumn{2}{|c|}{0.3} & \multicolumn{2}{|c|}{0.4} \\
\hline \multirow{2}{*}{$\begin{array}{l}\text { Atazanavir } \\
\text { sulfate } \\
\left(\mu \mathrm{g} \mathrm{mL} L^{-1}\right)\end{array}$} & \multicolumn{3}{|c|}{ Concentration found $\left(\mu \mathrm{g} \mathrm{mL}^{-1}\right)^{\mathrm{b}}$} & \multicolumn{2}{|c|}{ RSD (\%) } & \multicolumn{2}{|c|}{$\begin{array}{c}\text { Model } \\
\text { recovery (\%) }\end{array}$} \\
\hline & & Intra-day & Inter-day & Intra-day & Inter-day & Intra-day & Inter-day \\
\hline 40.0 & & 40.4 & 40.3 & 0.5 & 0.7 & 101.0 & 100.8 \\
\hline 50.0 & & 50.3 & 50.1 & 0.6 & 0.6 & 100.6 & 100.2 \\
\hline 60.0 & & 60.4 & 60.2 & 0.5 & 0.7 & 100.7 & 100.3 \\
\hline
\end{tabular}

a Atazor capsules; concentration upon label claim.

${ }^{\mathrm{b}}$ Mean value, $n=6$.

established were $10 \%$ organic modifier, $0.4 \mathrm{~mL} \mathrm{~min}^{-1}$ flow rate and $6-\mu \mathrm{L}$ injection volume. Mobile phase was run in the following gradient percentage of acetonitrile, organic modifier: initial $10 \%$, 4-5 $\min 50 \%$, 7-8 $\min 10 \%$. Graphical optimization was used to explore

Table IV. Comparison of the new method with the existing ones

\begin{tabular}{|c|c|c|}
\hline Mobile phase & $\begin{array}{l}\text { Retention } \\
\text { time (min) }\end{array}$ & Ref. \\
\hline Phosphate buffer (pH 6)-acetonitrile $(43: 57, V / V)$ & 16.20 & 34 \\
\hline Solvent A: $\mathrm{KH}_{2} \mathrm{PO}_{4}$ buffer $\left(0.02 \mathrm{~mol} \mathrm{~L}^{-1}, \mathrm{pH} 3.5\right)$, solvent $\mathrm{B}$ : acetonitrile & 12.5 & 35 \\
\hline $\begin{array}{l}\text { Mobile phase A: } 0.01 \mathrm{~mol} \mathrm{~L}^{-1} \mathrm{KH}_{2} \mathrm{PO}_{4} \text { (pH 3.6), mobile phase B: } \\
\text { acetonitrile }\end{array}$ & 9.18 & 36 \\
\hline $\mathrm{MeOH}-\mathrm{H}_{2} \mathrm{O}(9: 1, V / V)$ pH 3.55 (with HAc) & 8.32 & 8 \\
\hline $55 \%$ acetonitrile, $45 \%$ water, $0.15 \%$ HAc, $4 \mathrm{mmol} \mathrm{L}^{-1} \mathrm{NH}_{4} \mathrm{Ac}$ & 8.30 & 37 \\
\hline $\begin{array}{l}0.02 \mathrm{~mol} \mathrm{~L}^{-1} \mathrm{NH}_{4} \mathrm{H}_{2} \mathrm{PO}_{4} \text { buffer-acetonitrile-MeOH }(30: 25: 45, V / V), \mathrm{pH} \\
2.5 \text { (with } \mathrm{H}_{3} \mathrm{PO}_{4} \text { ) }\end{array}$ & 3.00 & 9 \\
\hline Solvent A: $10 \mathrm{mmol} \mathrm{L}^{-1} \mathrm{NH}_{4} \mathrm{Ac}$, solvent B: acetonitrile & 5.19 & This paper \\
\hline
\end{tabular}


the design space/MODR. Design space (yellow area) indicated the region where changes to the optimized conditions will be tolerated and will be within the operable quality (Fig. 5), thus, confirming the robustness of the method for the intended use.

a)

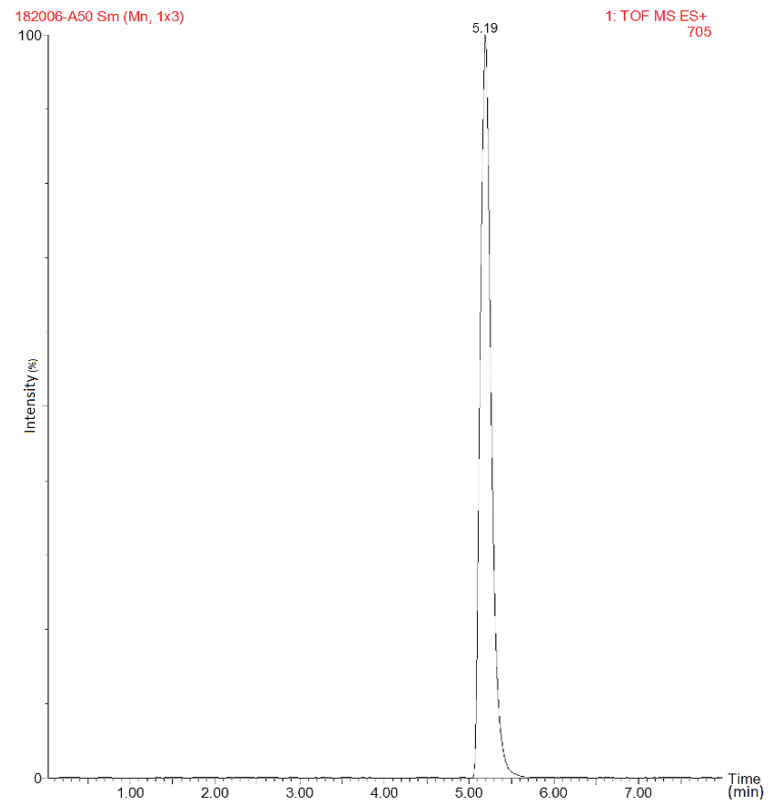

b)

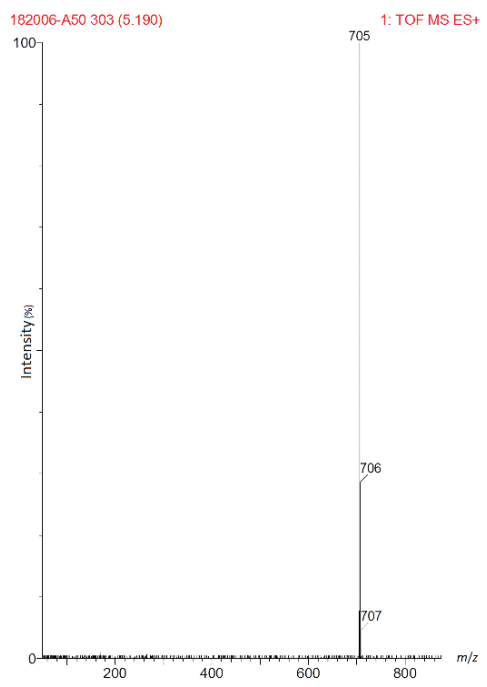

Fig. 6. a) TIC of atazanavir sulfate eluted at $5.19 \mathrm{~min}, \mathrm{~b}$ ) mass spectrum of the eluted peak.

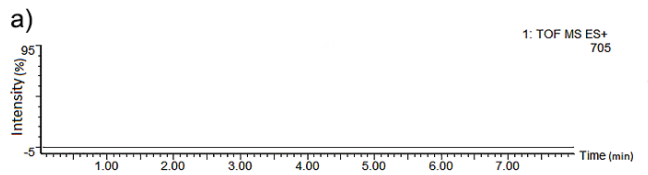

d)

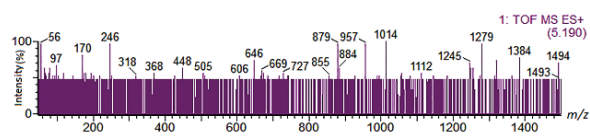

b)

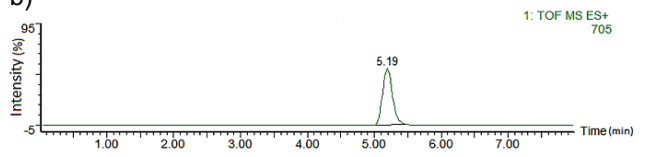

e)

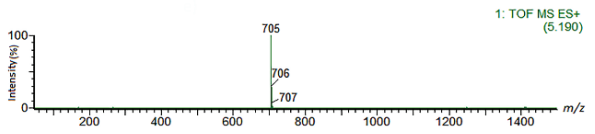

c)

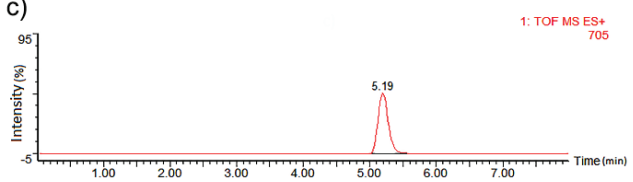

f)

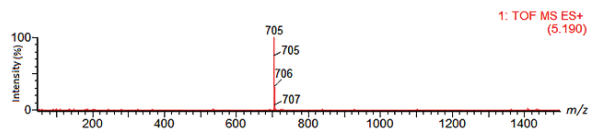

Fig. 7. TIC of: a) mobile phase (blank), b) standard atazanavir sulfate, c) commercial capsule of atazanavir sulfate and $\mathrm{d}-\mathrm{f}$ ) their respective mass spectra. 
C. Saha et al.: Development and validation of a UPLC-MS method for determination of atazanavir sulfate by the "analytical quality by design" approach, Acta Pharm. 70 (2020) 17-33.

a)

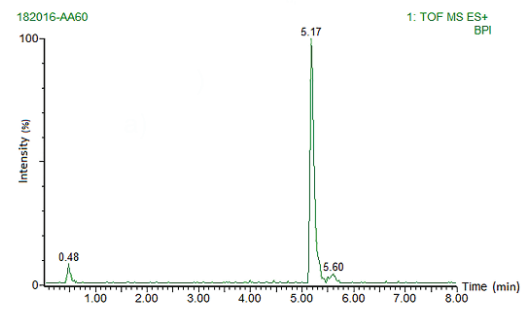

c)

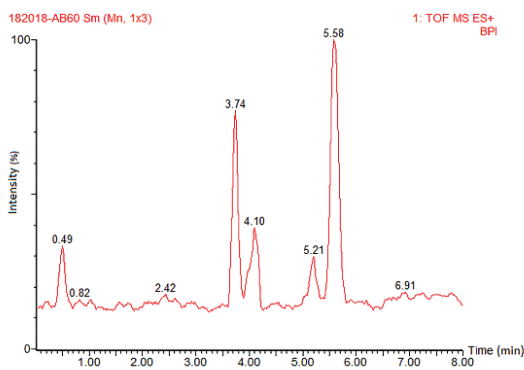

e)

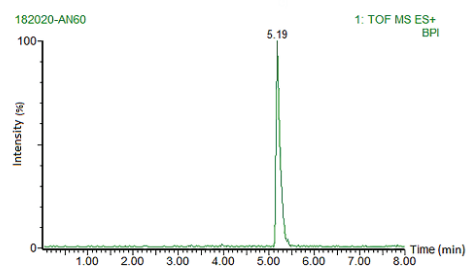

g)

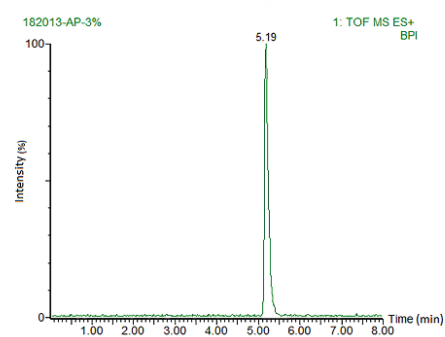

b)

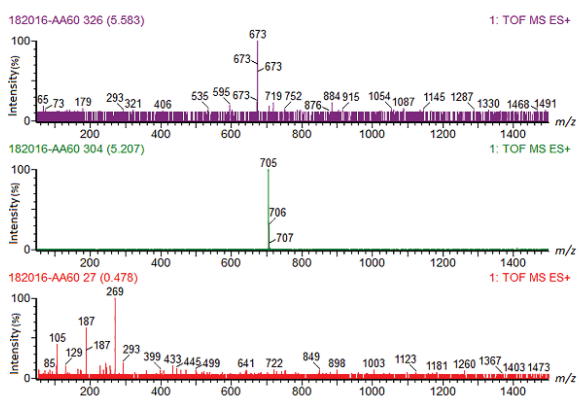

d)

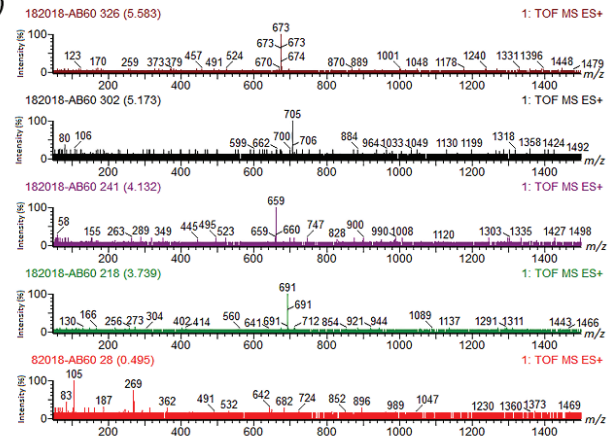

f)

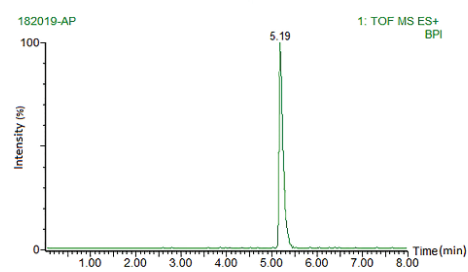

h)

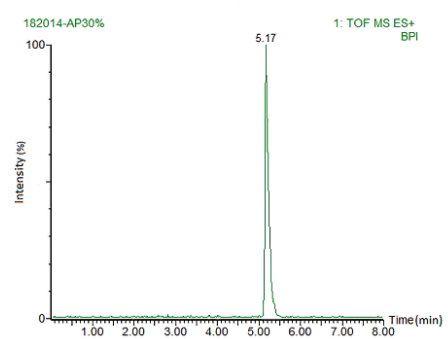

Fig. 8. a) BPI chromatogram of acidic degradation of atazanavir sulfate, b) mass spectra of eluted peaks from acidic degradation of atazanavir sulfate, c) BPI chromatogram of basic degradation of atazanavir sulfate, d) mass spectra of eluted peaks from basic degradation of atazanavir sulfate, e-h) BPI chromatograms of thermal, photolytic, $3 \% \mathrm{H}_{2} \mathrm{O}_{2}$ oxidative and $30 \% \mathrm{H}_{2} \mathrm{O}_{2}$ oxidative degradation of atazanavir sulfate, resp. 
Under optimized conditions, atazanavir sulfate was eluted at $5.19 \mathrm{~min}$; the $705 \mathrm{~m} / \mathrm{z}$ value from the mass spectrum confirmed the presence of atazanavir sulfate without any interference. Fig. 6a shows the total ion chromatogram (TIC) and Fig. $6 \mathrm{~b}$ the mass spectrum of the eluted peak.

\section{Method validation}

The developed analytical method was linear in the range of $10-90 \mu \mathrm{g} \mathrm{mL}^{-1}$. The calibration plot statistically proved the linearity $\left(y=56.18 x+0.3573 ; R^{2}=0.9999\right)$ indicating good linear fit. The method was reported to be accurate with recovery between $100.2-$ $101.0 \%$ and precise with RSD ranging from $0.2-0.7 \%$ (Table III). Calculated LOD and LOQ of atazanavir sulfate were 2.68 and $8.14 \mathrm{~g} \mathrm{~mL}^{-1}$, resp. The method was shown to be selective with the analyte being identified as a sharp peak at 5.19 min both in standard and sample solutions without any interference from the blank (Fig. 7). The optimized and validated method proved to be better than several existing liquid chromatographic methods in terms of retention time and simple mobile phase composition (see Table IV).

Further, the systematic approach to optimized method conditions and statistical justification make the entire process distinct from the regular practice.

The proposed method was applied to the assay of a commercial capsule formulation. The mean \% assay was $101.0 \%$ of the declared amount with RSD of $0.5 \%(n=6)$.

\section{Stability testing (stress testing)}

Stress testing studies showed atazanavir sulfate to degrade under acidic and basic conditions while being stable under thermal, oxidative and photolytic experimental conditions. Fig. 8 shows the results of degradation through base peak intensity (BPI), for it is much cleafer to view all degradation peaks unlike in TIC.

\section{CONCLUSIONS}

Unlike the existing approaches for method development, the AQbD approach to method development made the entire process rational, systematic and embedded robustness within the method. The proposed method achieved the ATP by systematically identifying the risk factors and optimizing them to perceive the method conditions best fitting the defined CQAs. The method gave a detailed insight into the benefits of screening factors before optimization, thus reducing significant factors to organic modifier percent, flow rate and injection volume. Optimization using experimental design founded the method conditions, which was justified by statistical analysis. Following the established design space during method development can control experimental errors. Statistical significance of the method conditions along with satisfactory alignment to validation guidelines made the method sustainable and reflected its reliability. This approach shows that methodical planning and orderly execution can reduce the risk, experimental burden and errors, and thus its application to various research areas is foreseen.

Acknowledgements. - The authors are indebted to the University of Mysore, Institution of Excellence (IOE), for their laboratory assistance.

Supplementary material available upon request. 
Acronyms, abbreviations, symbols. - Ac - acetate, ADC - analog-to-digital, AQbD - analytical quality by design, ATP - analytical target profile, BPI - base peak intensity, BBD - Box-Behnken design, BEH - ethylene bridged hybrid, CMPs - critical method parameters, CQAs - critical quality attributes, DOE - design of experiments, FMEA - failure mode and effects analysis, FFD - fraction factorial design, $\mathrm{MeOH}$ - methanol, MODR - method operable design region, OFAT - one factor at a time, PTFE - polytetrafluoroethylene, QbD - quality by design, QTMP - quality target method profile, RPN - risk priority number, TIC - total ion chromatograms

\section{REFERENCES}

1. J. La Bonte, J. Lebbos, A. Raja and P. Kirkpatrick, Infectious Diseases, Nat. Rev. Drug Discov. 3 (2004) S26-S32; https://doi.org/10.1038/nrd1409

2. B. Hughes, Tapping into combination pills for HIV, Nat. Rev. Drug Discov. 8 (2009) 439-440; https:// doi.org/10.1038/nrd2917

3. A. Raja, J. Lebbos and P. Kirkpatrick, Atazanavir sulphate, Nat. Rev. Drug Discov. 2 (2003) 857-858; https://doi.org/10.1038/nrd1232

4. K. Geetha Bhavani, K. Bala Murali Krishna, N. Srinivasu, D. Ramachandran, N. V. V. S. S Raman and B. Hari Babu, Determination of genotoxic impurity in atazanavir sulphate drug substance by LC-MS, J. Pharm. Biomed. Anal. 132 (2017) 156-158; https://doi.org/10.1016/j.jpba.2016.09.025

5. K. Watanabe, E. Varesio and G. Hopfgartner, Parallel ultra high pressure liquid chromatographymass spectrometry for the quantification of HIV protease inhibitors using dried spot sample collection format, J. Chromatogr. B 965 (2014) 244-253; https://doi.org/10.1016/j.jchromb.2014.05.008

6. S. Colombo, N. Guignard, C. Marzolini, A. Telenti, J. Biollaz and L. A. Decosterd, Determination of the new HIV-protease inhibitor atazanavir by liquid chromatography after solid-phase extraction, J. Chromatogr. B 810 (2004) 25-34; https://doi.org/10.1016/j.jchromb.2004.07.008

7. A. Loregian, S. Pagni, E. Ballarin, E. Sinigalia, S. G. Parisi and G. Palù, Simple determination of the HIV protease inhibitor atazanavir in human plasma by high-performance liquid chromatography with UV detection, J. Pharm. Biomed. Anal. 42 (2006) 500-505; https://doi.org/10.1016/j. jpba.2006.04.031

8. S. Dey, S. S. Patro, N. S. Babu, P. N. Murthy and S. K. Panda, Development and validation of a stability-indicating RP-HPLC method for estimation of atazanavir sulfate in bulk, J. Pharm. Anal. 7 (2017) 134-140; https://doi.org/10.1016/j.jpha.2013.12.002

9. C. H. Bhirud and S. N. Hiremath, Stability indicating RP-HPLC method for the determination of atazanavir sulphate in bulk and dosage form, Drug Invent. Today 5 (2013) 81-86; https://doi. org/10.1016/j.dit.2013.05.008

10. L. Else, V. Watson, J. Tjia, A. Hughes, M. Siccardi, S. Khoo and D. Back, Validation of a rapid and sensitive high-performance liquid chromatography-tandem mass spectrometry (HPLC-MS/MS) assay for the simultaneous determination of existing and new antiretroviral compounds, J. Chromatogr. B 878 (2010) 1455-1465; https://doi.org/10.1016/j.jchromb.2010.03.036

11. M. Mirochnick, B. M. Best, A. M. Stek, E. V. Capparelli, C. Hu, S. K. Burchett, S. S. Rossi, E. Hawkins, M. Basar, E. Smith and J. S. Read, Atazanavir pharmacokinetics with and without tenofovir during pregnancy, JAIDS J. Acquir. Immune Defic. Syndr. 56 (2011) 412-419; https://doi. org/10.1097/QAI.0b013e31820fd093

12. S. Goutelle, T. Baudry, M.-C. Gagnieu, A. Boibieux, J.-M. Livrozet, D. Peyramond, C. Chidiac, M. Tod and T. Ferry (on behalf of the Lyon HIV Cohort Study Group), Pharmacokinetic-pharmacodynamic modeling of unboosted atazanavir in a cohort of stable HIV-infected patients, Antimicrob. Agents Chemother. 57 (2013) 517-523; https://doi.org/10.1128/AAC.01822-12

13. C. S. Venuto, K. Mollan, Q. Ma, E. S. Daar, P. E. Sax, M. A. Fischl, A. C. Collier, K. Y. Smith, C. Tierney and G. D. Morse (on behalf of AIDS Clinical Trial Group Study A5202 Team), Sex differences in 
C. Saha et al.: Development and validation of a UPLC-MS method for determination of atazanavir sulfate by the "analytical quality by design" approach, Acta Pharm. 70 (2020) 17-33.

atazanavir pharmacokinetics and associations with time to clinical events: AIDS Clinical Trials Group Study A5202, J. Antimicrob. Chemother. 69 (2014) 3300-3310; https://doi.org/10.1093/jac/dku303

14. D. K. Lloyd and J. Bergum, Application of quality by design (QbD) to the development and validation of analytical methods, in: Specification of Drug Substances and Products - Development and Validation of Analytical Methods (C. M. Riley, T. W. Rosanske and S. R. Rabel Riley, Eds.), Elsevier, Amsterdam 2014, pp. 29-72.

15. B. Kelley, M. Cromwell and J. Jerkins, Integration of QbD risk assessment tools and overall risk management, Biologicals 44 (2016) 341-351; https://doi.org/10.1016/j.biologicals.2016.06.001

16. P. K. Sahu, N. R. Ramisetti, T. Cecchi, S. Swain, C. S. Patro and J. Panda, An overview of experimental designs in HPLC method development and validation, J. Pharm. Biomed. Anal. 147 (2018) 590-611; https://doi.org/10.1016/j.jpba.2017.05.006

17. M. de Matas, T. De Beer, S. Folestad, J. Ketolainen, H. Lindén, J. A. Lopes, W. Oostra, M. Weimer, P. Öhrngren and J. Rantanen, Strategic framework for education and training in Quality by Design (QbD) and process analytical technology (PAT), Eur. J. Pharm. Sci. 90 (2016) 2-7; https://doi. org/10.1016/j.ejps.2016.04.024

18. International Conference on Harmonisation of Technical Requirements for Registration of Pharmaceuticals for Human Use, ICH Harmonised Tripartite Guideline, Validation of Analytical Procedures: Pharmaceutical Development Q8 (R2), Current Step 4 version, August 2009; http://www.ich.org/fileadmin/Public_Web_Site/ICH_Products/Guidelines/Quality/Q8_R1/Step4/Q8_R2_Guideline.pdf; last access date March 10, 2018.

19. International Conference on Harmonisation of Technical Requirements for Registration of Pharmaceuticals for Human Use, ICH Harmonised Tripartite Guideline, Validation of Analytical Procedures: Quality Risk Management Q9, Current Step 4 version, November 2005; http://www.ich.org/fileadmin/Public_Web_Site/ICH_Products/Guidelines/Quality/Q9/Step4/Q9_Guideline.pdf; last access date March 10, 2018.

20. International Conference on Harmonisation of Technical Requirements for Registration of Pharmaceuticals for Human Use, ICH Harmonised Tripartite Guideline, Validation of Analytical Procedures: Pharmaceutical Quality System Q10, Current Step 4 version, June 2008; http://www.ich.org/fileadmin/Public_Web_Site/ICH_Products/Guidelines/Quality/Q10/Step4/Q10_Guideline.pdf; last access date March 10, 2018.

21. J. Kochling, W. Wu, Y. Hua, Q. Guan and J. Castaneda-Merced, A platform analytical quality by design (AQbD) approach for multiple UHPLC-UV and UHPLC-MS methods development for protein analysis, J. Pharm. Biomed. Anal. 125 (2016) 130-139; https://doi.org/10.1016/j.jpba.2016.03.031

22. G. L. Reid, J. Morgado, K. Barnett, B. Harrington, J. Wang, J. Harwood and D. Fortin, Analytical Quality by Design (AQbD) in pharmaceutical development, Am. Pharm. Rev. 16 (2013); https:// www.americanpharmaceuticalreview.com/Featured-Articles/144191-Analytical-Quality-by-Design-AQbD-in-Pharmaceutical-Development/; last access date December 26, 2018.

23. P. S. Sandhu, S. Beg, R. Kumar, O. P. Katare and B. Singh, Analytical QbD-based systematic bioanalytical HPLC method development for estimation of quercetin dihydrate, J. Liq. Chromatogr. Relat. Technol. 40 (2017) 506-516; https://doi.org/10.1080/10826076.2017.1329744

24. A. Dispas, H. T. Avohou, P. Lebrun, P. Hubert and C. Hubert, 'Quality by Design' approach for the analysis of impurities in pharmaceutical drug products and drug substances, Trends Anal. Chem. 101 (2017) 24-33; https://doi.org/10.1016/j.trac.2017.10.028

25. T. Schofield, D. Robbins and G. Miró-Quesada, Critical Quality Attributes, Specifications, and Control Strategy, in Quality by Design for Biopharmaceutical Drug Product Development (Eds. F. Jameel, S. Hershenson, M. A. Khan and S. Martin-Moe) /Advances in the Pharmaceutical Sciences Series, AAPS, Vol. 18 (Eds. D. J. A. Crommelin and R. A. Lipper)/Springer, New York, pp. 511-535.

26. U. S. Food and Drug Administration (FDA), Center for drug evaluation and research (CDER), Reviewer Guidance-Validation of Chromatographic Methods, November 1994; https://www.fda.gov/ downloads/Drugs/Guidances/UCM134409.pdf; last access date December 26, 2018 
27. What is peak tailing? Chromatogr. Today, August 8, 2014; https://www.chromatographytoday.com/ news/autosamplers/36/breaking-news/what-is-peak-tailing/31253; last access date December 26, 2018.

28. International Conference on Harmonisation of Technical Requirements for Registration of Pharmaceuticals for Human Use, ICH Harmonised Tripartite Guideline, Validation of Analytical Procedures: Text and Methodology, Q2 (R1), Current Step 4 version, November 2005; https://www.ich.org/fileadmin/Public_Web_Site/ICH_Products/Guidelines/Quality/Q2_R1/Step 4/Q2_R1__Guideline.pdf; last access date $\overline{\text { March } 10,2018 .}$

29. T. Sharma, R. K. Khurana, A. Jain, O. P. Katare and B. Singh, Development of a validated liquid chromatographic method for quantification of sorafenib tosylate in the presence of stress-induced degradation products and in biological matrix employing analytical quality by design approach, Biomed. Chromatogr. 32 (2018) e4169; https://doi.org/10.1002/bmc.4169

30. N. K. Garg, G. Sharma, B. Singh, P. Nirbhavane and O. P. Katare, Quality by Design (QbD)-based development and optimization of a simple, robust RP-HPLC method for the estimation of methotrexate, J. Liq. Chromatogr. Relat. Technol. 38 (2015) 1629-1637; https://doi.org/10.1080/10826076.2015. 1087409

31. International Conference on Harmonisation of Technical Requirements for Registration of Pharmaceuticals for Human Use, ICH Harmonised Tripartite Guideline, Validation of Analytical Procedures: Stability Testing of New Drug Substances and Products Q1A(R2), Current Step 4 version, February 2003; http://www.ich.org/fileadmin/Public_Web_Site/ICH_Products/Guidelines/Quality/Q1A_ R2/Step4/Q1A_R2__Guideline.pdf; last access date March 10, 2018.

32. International Conference on Harmonisation of Technical Requirements for Registration of Pharmaceuticals for Human Use, ICH Harmonised Tripartite Guideline, Validation of Analytical Procedures: Stability Testing: Photostability Testing of New Drug Substances and Products Q1B, Current Step 4 version, November 1996; http://www.ich.org/fileadmin/Public_Web_Site/ICH_Products/Guidelines/ Quality/Q1B/Step4/Q1B_Guideline.pdf; last access date March 10, 2018.

33. L. Zhang and S. Mao, Application of quality by design in the current drug development, Asian J. Pharm. Sci. 12 (2017) 1-8; https://doi.org/10.1016/j.ajps.2016.07.006

34. A. Loregian, S. Pagni, E. Ballarin, E. Sinigalia, S. G. Parisi and G. Palù, Simple determination of the HIV protease inhibitor atazanavir in human plasma by high-performance liquid chromatography with UV detection, J. Pharm. Biomed. Anal. 42 (2006) 500-505; https://doi.org/10.1016/j. jpba.2006.04.031

35. S. R. Chitturi, Y. S. Somannavar, B. G. Peruri, S. Nallapati, H. K. Sharma, S. R. Budidet, V. K. Handa and H. B. Vurimindi, Gradient RP-HPLC method for the determination of potential impurities in atazanavir sulfate, J. Pharm. Biomed. Anal. 55 (2011) 31-47; https://doi.org/10.1016/j. jpba.2011.01.002

36. M. K. V. V. N. Mantripragada, S. V. Rao, V. V. S. Nutulapati and B. P. V. Mantena, Simultaneous determination of impurities of atazanavir and ritonavir in tablet dosage form by using reversedphase ultra performance liquid chromatographic method, J. Chromatogr. Sci. 56 (2018) 270-284; https://doi.org/10.1093/chromsci/bmx110

37. N. Phung, K. Kuncze, H. Okochi, A. Louie, L. Z. Benet, I. Ofokotun, D. W. Haas, J. S. Currier, T. D. Chawana, A. N. Sheth, P. Bacchetti, M. Gandhi and H. Horng, Development and validation of an assay to analyze atazanavir in human hair via liquid chromatography/tandem mass spectrometry, Rapid Commun. Mass Spectrom. 32 (2018) 431-441; https://doi.org/10.1002/rcm.8058 